\title{
Urtica Dioica and Lamium Album Decrease Glycogen Synthase Kinase-3 beta and Increase K-Ras in Diabetic Rats
}

\author{
Mahmood Abedinzade 1, Mohammad Rostampour 2,3, Ebrahim Mirzajani ${ }^{2,4}$, Zahra \\ Bostani Khalesi ${ }^{5}$, Tahere Pourmirzaee ${ }^{1}$, Korosh Khanaki ${ }^{1 *}$ \\ ${ }^{1}$ Medical Biotechnology Research Center, School of Paramedicine, Guilan University of Medical Sciences, Rasht, Iran \\ ${ }^{2}$ Cellular and Molecular Research Center, Faculty of Medicine, Guilan University of Medical Sciences, Rasht, Iran \\ ${ }^{3}$ Department of Physiology, Faculty of Medicine, Guilan University of Medical Sciences, Rasht, Iran \\ ${ }^{4}$ Department of Biochemistry and Biophysics, Faculty of Medicine, Guilan University of Medical Sciences, Rasht, Iran \\ ${ }^{5}$ Department of Obstetrics and Midwifery, Faculty of Nursing and Midwifery, Guilan University of Medical Sciences, Rasht, Iran
}

\section{Key Words}

Diabetes, Herb, Signal Pathway, Gsk-3 beta, Urtica dioica, Lamium album.

\section{Abstract \\ Objectives: The aim of the present work is evaluating the special effects of Urtica Dioica and Lamium Album on the serum level of K-Ras and GSK-3 beta in diabetic rats.}

Methods: In the present experimental study, 32 male Wistar rats randomly divided into 4 groups (Group I: normal control rats; receiving daily PBS, Group 2: diabetic control rats; receiving single dose of streptozotocin (60 mg/kg) and daily PBS, Group 3: Diabetic rats treated with $100 \mathrm{mg} / \mathrm{kg}$ of hydroalcoholic extract of the $U$. dioica, Group 4: Diabetic rats treated with $100 \mathrm{mg} / \mathrm{kg}$ of hydroalcoholic extract of L. Album. Diabetes-induced by an intraperitoneal injection of streptozotocin $(60 \mathrm{mg} /$ $\mathrm{kg}$ ). On the 14 th day of treatment, the weight, fasting blood sugar (FBS) and on 28 th day blood glucose, K-Ras and GSK3 beta was measured.

Results: In diabetic group blood GSK- 3 beta increase in comparison to control group $(\mathrm{P}<0.05)$, also blood $\mathrm{K}$-Ras decrease in the diabetic group $(\mathrm{P}<0.05)$. Both

Received: Mar 15, 2019 Reviewed: Jun 13, 2019 Accepted: Nov 25, 2019

(@) This is an Open-Access article distributed under the terms of the Creative Common Attribution Non-Commercial License (http://creativecommons.org/licenses/by-nc/4.0/) which permits unrestricted noncommercial use, distribution, and reproduction in any medium, provided the original work is properly cited.

(2) This paper meets the requirements of KS X ISO 9706, ISO 9706-1994 and ANSI/NISO Z39.48-1992 (Permanence of Paper). extracts reduced GSK-3 beta level, however, this reduction was only statistically significant by U.dioica $(\mathrm{P}<0.05)$. Compared to diabetic group, blood K-Ras level increased by both extract $(\mathrm{P}<0.05)$. Also diabetes induction increase blood glucose levels and both extracts decrease its level significantly $(\mathrm{P}<0.05)$.there is no significant differences among both extract effects on blood glucose, and K-Ras.

Conclusion: For the first time shown that both extracts by regulating GSK-3 beta and K-Ras improve blood glucose level. More studies are needed to determine all the effects of these herbs.

\section{Introduction}

According to an estimate, the number of diabetic people in the world would increase to around 415 million by 2025 [1]. Despite extensive research on this disease, it is necessary to find new methods for early diagnosis, treatment or prevention of complications of diabetes with the goal of improving the health of the community and reducing the cost of health care and mortality resulting from it.

In the Islamic Republic of Iran with a population of over 80 million, Diabetes is prevalent (at least $\mathbf{8 \%}$ ). As the young Iranian population grows, the incidence of diabetes will increase rapidly [2].

Glycogen Synthase Kinase 3 beta (GSK-3 beta) has 
been identified as the regulator of glycogen metabolism, and growth factors [3]. The PI3K / AKT pathway is activated in response to many factors including insulin and other growth factors, and the activation of this route leads to the phosphorylation and inactivation of GSK-3 beta. A major substrate of GSK-3 beta, the glycogen synthase, catalyzes the final phase of glycogen synthesis. The glycogen synthase phosphorylation by active GSK-3 beta prevents glycogen synthesis. Therefore, the deactivation of GSK-3 beta by PI3K / AKT pathway develops the storage of glucose as glycogen, which ultimately leads to a decrease in blood glucose [4].

Ras proteins are small GTPases enzymes which act as the main regulators of multiple signaling pathways. Their roles include growth control, migration, cellular connectivity, survival, and differentiation. The three types of Ras proteins include $\mathrm{H}$-Ras, N-Ras, K-Ras. Ras proteins in response to growth factor or insulin activate several intracellular pathways. The K-Ras pathway activates a variety of downstream signaling molecules such as PI3K $[5,6]$.

Our previous serial research on the effects of U.dioica and L.album in diabetic rats has had interesting results (7-12), such as the modification of hepatic enzyme, the regulation of serum IGF-1 level, Cyclooxygenase-2 (Cox2) and Caspase-3 gene expression in the liver and kidney, tracheal smooth muscle cell relaxation by Lamium album. To increase our knowledge of the functional mechanisms of these two plants, in the present study, for the first time, the effects of these two extracts on blood GSK-3 beta and $\mathrm{K}$-Ras in diabetic rats were studied.

\section{Materials and Methods}

\subsection{Animals}

In this study, male adult Wistar rats weighing 250-350 $\mathrm{g}$ were used. This research was approved by the ethical committee of Guilan University of Medical Sciences (IR. GUMS.REC.1395.222) (Rasht, Iran).

\subsection{Diabetes induction}

This procedure performed according to the Mohseni Mehran et al. study [7]. In summary, for the induction of diabetes, Streptozotocin (STZ) was injected intraperitoneally at a dose of $60 \mathrm{mg} / \mathrm{kg}$. Then, after 3 days (day 0), blood glucose was measured and value $\geq 300 \mathrm{mg} / \mathrm{dl}$ was considered as diabetic.

\subsection{Plant material and extraction proce- dure}

Collection of aerial parts of two used plants and confirmation of their herbarium code were done according to our previous studies [9].

\subsection{Study Design}

All 32 rats were randomly arranged into four groups, each group containing seven rats as similar to our previous work [7]. Group 1 (normal), group 2 (diabetic), group 3 diabetic treated by $100 \mathrm{mg} / \mathrm{kg} / 28$ day U.dioica and group 4 diabetic treated by $100 \mathrm{mg} / \mathrm{kg} / 28$ day L.album On the 14 th and the 28th day of treatment, the weight and fasting blood sugar (FBS) was measured. Also, blood serum collected and freeze at -20 for measuring plasma levels of GSK-3 beta and K-Ras levels by Elisa method.

\subsection{GSK-3 beta measurement}

The level of serum GSK-3 beta (Total and Phosphorylated) was measured using an enzyme-linked immunosorbent assay (ELISA) kit (My Biosource, cat number MBS 7251608-96 test) and ELISA reader (Stat Fax, USA) in a single run. This kit was based on sandwiched Elisa.

\subsection{K-Ras measurement}

The serum level of K-Ras was determined by using ELISA Kit (My Biosource, 0844859-48 strip) and ELISA reader (Stat Fax, USA) in a single run. This kit was based on standard sandwich Elisa. In brief, an antibody specific for K-Ras had been pre-coated onto a 48-well plate (12 x 4 well strips). Standards or serum samples were added to the wells, incubated. Absorbance was read at $450 \mathrm{~nm}$ which was quantitatively proportional to the serum level of K-Ras.

\subsection{Statistical analysis}

Data are presented as Mean \pm SEM. Data distribution was evaluated by the Shapiro-Wilk test. Data were normally distributed and the groups had equal variances. One way ANOVA followed by the Tukey post hoc test was used for comparison between groups. In each group, the FBS level among different times was compared using repeated measure ANOVA. $\mathrm{P}<0.05$ was considered as statistically significant. The analysis was done using SPSS software version 16.

\section{Results}

\subsection{Fasting blood glucose measurements}

Fasting blood glucose was considerably increased in diabetic group in comparison to healthy control group ( $\mathrm{P}<0.0001)$. U. dioica extract and L. Album significantly decreased blood glucose levels significantly decreased blood glucose level on the 14th and 28th days in diabetic rats $(\mathrm{P}<0.0001)$ (Table 1). 
Table 1 The blood glucose level in studied groups.

\begin{tabular}{|l|c|c|c|}
\hline Groups & Day 0 & Day 14 & Day 28 \\
\hline Control & $112 \pm 9^{*}$ & $89 \pm 6^{*}$ & $106 \pm 7^{*}$ \\
\hline Diabetic & $530 \pm 12^{\#}$ & $515 \pm 7^{\#}$ & $499 \pm 11^{\#}$ \\
\hline U. dioica & $390 \pm 15^{*}$ & $255 \pm 8^{*}$ & $211 \pm 4.5^{*}$ \\
\hline L. album & $422 \pm 13^{*}$ & $220 \pm 7.5^{*}$ & $200 \pm 5^{*}$ \\
\hline
\end{tabular}

Values are presented as Mean \pm SEM.

\# $\mathrm{P}<0.0001$ by comparison with control rats.

* $\mathrm{P}<0.0001$ by comparison with diabetic rats.

Table 2 Effect of $U$. dioica and $L$. album on Serum level of GSK-3 beta and K-Ras

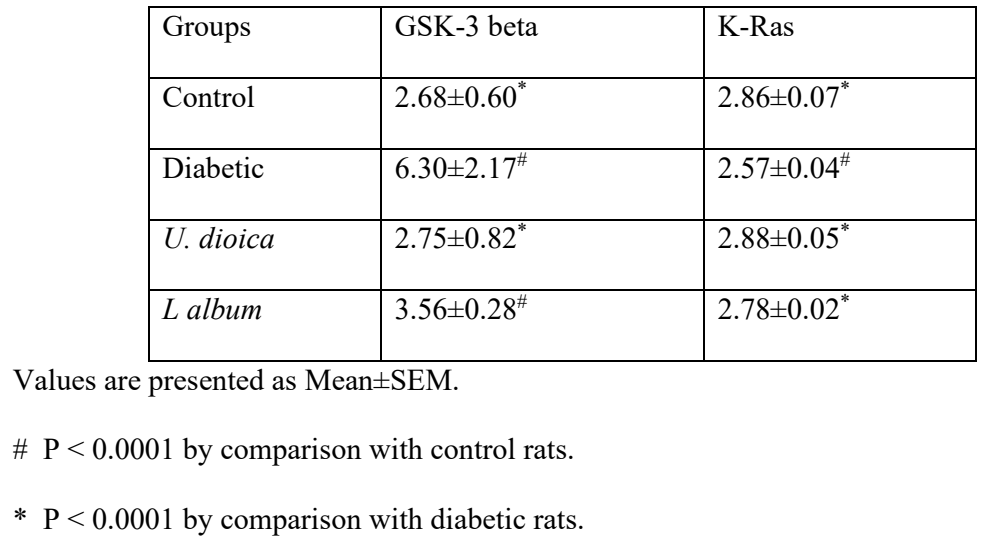

\subsection{Measurement of GSK3 beta and K-Ras level in different groups.}

The serum levels of GSK-3 beta significantly increased in diabetic group compared with healthy controls $(\mathrm{P}<$ 0.0001). Both extracts reduced GSK-3 beta level, however, this reduction was only statistically significant by $U$.dioica $(\mathrm{P}<0.0001)$.

Also, the level of serum K-Ras remarkably decreased in diabetic group as compared to healthy control group (P $<0.0001)$. U. dioica and L. Album significantly increased the K-Ras level in the diabetic rats $(\mathrm{P}<0.0001)$ (Table 2). No significant difference was observed in K-Ras level between diabetic rats exposed to U. dioica and L. album.

\section{Discussion}

This was the first study to assess the effects of U.dioica and L.album on GSK-3 beta and K-Ras. In the present study, blood glucose level decreased in diabetic groups treated with both extracts. This finding was in agreement with Mohseni Mehran et al. [7] study that showed U.dioca and L.album could decrease blood glucose in diabetic rats. Also, Pashazadeh and Rezaei showed similar results in diabetic rats [13]. Farzami et al. and Bnouham et al. demostrated that the hypoglycemic effect of U.dioca could be due to the increase in insulin release $[14,15]$.

It has been shown that GSK-3 beta regulates several cellular processes. Many studies showed that GSK-3 beta level increased in diabetic rats $[16,17]$. In the present study, the GSK-3 Beta elevated in diabetic groups, but both extracts decreased its level. Also, U. dioica and $L$. album decreased blood glucose level in diabetic rats indicating their ability to ameliorate blood glucose metabolism potentially with GSK3 inhibition. Yu et al. reported that GLUT4 and GSK3区 (downstream of PI3K) are the important proteins in controlling glucose uptake and storage and glycogen metabolism [19]. Therefore, the drugs regulating the above proteins could be promising in the treatment of Diabetes. U.dioica and L.album demonstrated to be effective in controlling high glucose and relieving the symptoms of DM patients. Previously, we found that U.dioica and L.album could decrease both serum glucose and lipid levels in STZ-induced diabetic rats [7]. However, the molecular mechanisms of these herbs still need to be explored. Hence, we showed the effect of U.dioica and L.album on diabetes condition by impacting on GSK-3 beta and its association with PI3K/Akt signaling pathway. 
As mentioned earlier, RAS proteins activate several intracellular pathways in response to growth factor or insulin. In this study, the serum level of K-Ras significantly decreased in diabetic group compared to control group. $U$. dioica and $L$. Album extracts significantly increased the enzyme level in diabetic rats. Our finding was in line with the result of Cline et al. that showed treatment with GSK-3 inhibitor lowered fasting hyperglycemia in diabetic rats; this study suggested that GSK-3 inhibition may represent an important new therapeutic target for the treatment of patients with diabetes [18].

\section{Conclusion}

It was found that the hypoglycemic properties demonstrated by U.dioica and L.album might be partly due to the decrease in GSK-3 beta and increase in K-Ras levels, although the involved molecular mechanisms need to be further examined.

\section{Financial support}

The authors wish to express their appreciation to the Research Deputy of Guilan University of Medical Sciences (Rasht, Iran) for financial support. All authors confirmed that there is no conflict of interest in the present study.

\section{Authors Contributions}

MA, KK, ZBK designed the study, wrote the protocol. MA and TP managed the acquisition of data. MA and KK performed the analysis and interpretation of data. MA and TP wrote the first draft of the manuscript. KK, MR, EM, ZBK performed a critical revision of the manuscript and managed the literature searches. MA, KK, ZBK did administrative, technical and mate $\neg$ rial support. All authors read and agreed on the final manuscript.

\section{Ethical approval}

All authors hereby declare that all experiments have been examined and approved by the appropriate ethics committee and have therefore been performed in accordance with the ethical standards laid down in the 1964 Declaration of Helsinki.

\section{References}

1. King H. Aubert RE, Herman WH. Global Burden of diabetes, 1995-2025: prevalence, numerical estimates, and projections. Diabetes Care. 1998.21:1414-31.

2. Esteghamati A. Prevalence of Diabetes and Impaired Fasting Glucose in the Adult Population of Iran. Diabetes Care. 2008;31:96-8.

3. Doble BW, Woodgett JR. GSK-3:tricks of the trade for a multi-tasking kinase. J cell Sci. 2003;116:1175-86

4. Christopher JP, Yaskaitis J and Beurel E. Glycogen Synthase kinas-(GSK-3):Inflammation, Diseases, and Therapeutics. Neurochem Res. 2007;32(4-5):577-95.

5. Krishnaraj R, lingam RS, Albert S. Ras oncogenes and their downstream targets. Biochemica et Bio physica Acta. 2007(1773)1177-95.

6. Schnieke S. oncogenic KRAS signaling in parcreatic cancer. British Journal of cancer(2014)111,817-822

7. Mohseni Mehrana M, Norasfard MR, Abedinzade M, Khanaki K. Lamium album or urtica dioica? Which is more effective in decreasing serum glucose, lipid and hepatic enzymes in streptozotocin induced diabetic rats: a comparative study. Afr J Trad Compl Alt Med. 2015; 12(5):84-8.

8. Jafarzade P, Mohseni Mehran S M, Moladoust H, Norasfard M R, Ghorbani A, Abedinzade M. Effect of Hydroalcoholic Extract of Anethum graveolens L. Seed on Tracheal Smooth Muscle Contractions in Male Rats. J Mazandaran Univ Med Sci. 2018;28(160):146-50.

9. Korosh Khanaki, Mahmood Abedinzade, Masoud Hamidi. Evaluation the effects of Urtica diocia and Lamium album extracts on cyclooxygenase- 2 and caspase- 3 gene expression in the diabetic rats. Pharmaceutical sciences. 2019;25:37-43.

10. Khanaki K, Abedinzade M, Gazor R, Norasfard MR, Jafari-Shakib R. Effects of Lamium album on mitochondrial oxidative stress in diabetic rats. Res Mol Med. 2017;5(2):913.

11. Khanaki K, Abedinzade M, Mohammadi M. the extract of Lamium album and urtica dioica increase insulin-like growth factor 1 level in streptozotocin- induced diabetic rats. ZJRMS. 2018,

12. Arefani S, Mohseni Mehran SM, Moladoust H, Norasfard MR, Ghorbani A, Abedinzade M. Effects of standardized extracts of Lamium album and Urtica dioica on rat tracheal smooth muscle contraction. J Pharmacopuncture. 2018;21(2):70-5.

13. Pashazadeh M AND Rezaei A. The effects of chronic oral lamium album consumption on blood levels of glucose and lipids in alloxan induced diabetic rats. International Journal of Pharmaceuticals Analysis. 2013;4(1):21-4.

14. Farzami B, Ahmadvand D, Vardasbi S, Majin FJ, Khaghani Sh. Induction of insulin secretion by a component of Urtica dioica leave extract in perifused Islets of Langerhans and its in vivo effects in normal and streptozotocin diabetic rats. J Ethnopharmacol. 2003;89(1):47-53.

15. Bnouham M, Merhfour FZ, Ziyyat A, Mekhfi H, Aziz M, Legssyer A Fitoterapia. Antihyperglycemic activity of the aqueous extract of Urtica dioica. 2003;74(7-8):677-81.

16. Nikoulina SE, Ciaraldi TP, Mudaliar S, Carter L, Johnson K, Henry RR. Inhibition of Glycogen Synthase Kinase 3 Im- 
proves Insulin Action and Glucose Metabolism in Human Skeletal Muscle. Diabetes. 2002;51:2190-8.

17. Clodfelder-Miller B, De Sarno P. Physiological and Pathological Changes in Glucose Regulate Brain Akt and Glycogen Synthase Kinase-3. J Biol Chem. 2005;280(48): 3972331.

18. Clyne GW, et al. Effects of a Novel Glycogen Synthase Kinase-3 Inhibitor on Insulin-Stimulated Glucose Metabolism in Zucker Diabetic Fatty (fa/fa) Rats. DIABETES. 2002;51:2903-10.

19. Yu N, Fang X, Xhao D, Mu Q. Anti-Diabetic Effects of Jiang Tang Xiao Ke Granule via PI3K/Akt Signalling Pathway in Type 2 Diabetes KKAy Mice. Plus one. 12 (1). 